\title{
Sistem Klasifikasi Kualitas Batu Boulder Berdasarkan Tekstur Berbasis Pengolahan Citra Digital
}

\author{
Rifqy Abdillah ${ }^{1}$, Fitri Marisa ${ }^{2}$, Dwi Purnomo ${ }^{3}$
}

\begin{abstract}
In the boulder stone mining (stone elephants), there are three kinds of rocks that dotted stones, rocks and stones pecelan well. Stone dotted with holes can worsen the quality of the stone. Determination of the quality of the stone boulder (stone elephants) can be done manually by visual observation. The manual system requires a long time and produce products that are inconsistent because of visual limitations, fatigue and differences in the perception of each observer.

In this thesis designed a classification system to determine the quality of the stone boulder (stone elephants) using texture analysis based digital image processing, to get the most accurate and objective. The image data taken that boulder rock sample (stone elephants) using the 8 MP camera phone. The algorithm used is the contrast stretching algorithm to improve image quality, as well as to the classification of the rock boulder (stone elephants) using the composition of the value of RGB image calibration number boulder stone (stone elephants) is.
\end{abstract}

The final results are output classification boulder stone (stone elephants) based on sample quality stone image we input. Making it easier for employees in determining the quality of the stones produced from the mine site.

Intisari - Dalam pertambangan batu boulder (batu gajah) terdapat tiga macam batu yaitu batu burik, batu baik dan batu pecelan. Batu burik yang berlubang dapat memperburuk kualitas batu. Penentuan kualitas batu boulder (batu gajah) dapat dilakukan secara manual dengan pengamatan visual. Sistem manual membutuhkan waktu yang lama dan menghasilkan produk yang tidak konsisten karena keterbatasan visual, kelelahan dan perbedaan persepsi masing-masing pengamat.

Pada skripsi ini dirancang sebuah sistem klasifikasi untuk mengetahui kualitas batu boulder (batu gajah) dengan menggunakan analisis tekstur berbasis pengolahan citra digital, untuk mendapatkan hasil yang tepat dan objektif. Data citra yang diambil yaitu sampel batu boulder (batu gajah) menggunakan kamera hp 8 MP. Algoritma yang digunakan adalah alogaritma contrast stretching untuk meningkatkan kualitas citra, serta untuk klasifikasi batu boulder (batu gajah) menggunakan komposisi nilai dari kalibrasi jumlah RGB citra batu boulder (batu gajah) tersebut.

Hasil akhir penelitian adalah output klasifikasi batu boulder (batu gajah) berdasarkan kualitas sample citra batu yang kita input. Sehingga memudahkan pegawai dalam menentukan kualitas batu yang dihasilkan dari lokasi tambang.

Kata Kunci- Pengolahan Citra Digital, Metode Contrast Stretching, Batu Boulder (Batu Gajah), Borland Delphi.

\section{PENDAHULUAN}

\section{A. Latar Belakang}

Pengetahuan dan pemanfaatan citra digital berkembang pesat, tidak hanya di bidang kedokteran, industri, kesehatan dan pertanian. Kemampuan pengolahan citra digital yang canggih memungkinkan dapat digunakan lebih efektif dan efisien untuk mengidentifikasi kualitas produk pertambangan yaitu menentukan kualitas batu boulder berdasarkan teksturnya.

Hasil pertambangan batu boulder merupakan salah satu bahan dalam bahan bangunan, seperti : pondasi rumah, pembuatan beton, jembatan. Kebutuhan batu boulder terus meningkaat sehingga kualitas batu perlu diperhatikan. Hal yang mempengaruhi kualitas batu boulder adalah kepadatan batu tersebut.

Dalam mengidentifikasi kualitas batu manusia memiliki banyak keterbatasan dalam ketilitian, konsistensi, dan daya tahan tubuh. Proses klasifikasi masih dilakukan secara manual yang menghasilkan produk kualitas tidak merata karena keterbatasan visual, kelelahan, dan perbedaan persepsi masing-masing pengamat.

Dengan pendekatan yang dikenal dengan nama pengenalan pola dapat membantu untuk mengenali objekobjek pada suatu gambar atau citra. Proses pengenalan ini dengan memberi inputan kepada computer berupa citra atau objek yang ingin dikenali, kemudian objek-objek tersebut akan dikenali ciri-cirinya dan diklasifikasikan sesuai kelasnya.

Metode contrast stretching yaitu menambahkan atau mengurangi pencahayaan agar citra tersebut lebih tajam dari citra. Penelitian sebelumnya sudah pernah dilakukan menggunakan masukkan berupa citra grayscale. Format citra adalah JPG, BMP, dan GIF. Hasil penelitian metode contrast stretching tidak banyak berpengaruh pada nilai pixel citra bila dilakukan dengan menggunakan auto level [14]. Maka penelitian ini akan mengembangkan perbaikan kualitas citra dengan metode yang sama dengan masukkan berupa citra RGB.

Dengan masalah diatas, untuk membantu mengklasifikasikan batu boulder dengan judul "SISTEM KLASIFIKASI KUALITAS BATU BOULDER (BATU GAJAH) BERDASARKAN TEKSTUR BERBASIS PENGOLAHAN CITRA DIGITAL" 


\section{LANDASAN TEORI}

\section{A. Batu Boulder (Batu Gajah)}

Material Batu Boulder (Batu Gajah) ini banyak sekali di gunakan untuk segala kontruksi bahan pengecoran di mulai dari yang ringan sampai kontruksi pengecoran yang sangat berat.

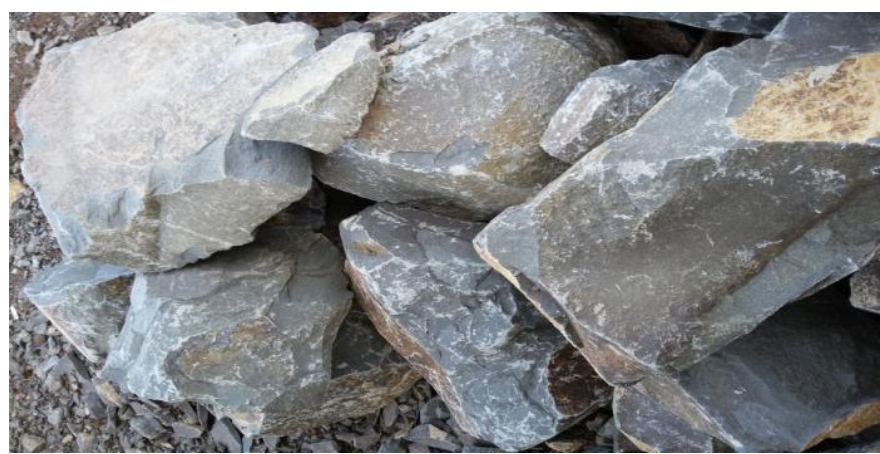

Gbr.1 Batu Boulder (Batu Gajah)

Kontruksi pengecoran seperti : Kontruksi Jalan Tol, Kontruksi Gedung Bertingkat, Landasan Pesawat Udara, Bantalan Kereta Api, Kontruksi Pelabuhan dan Dermaga serta kontruksi lainnya. Batu Boulder ini juga bisa di jadikan sebagai Kontruksi untuk Pengecoran atau Pembetonan. Ada juga Material Batu Boulder bisa di gunakan sebagai dasar badan jalan sebelum menggunakan material yang lain, serta sebagai Penyangga Bantalan Kereta Api, serta Penutup dan Pemberat Pipa di Dasat laut. Batu Boulder ini di ambil dari daerah pegunungan dengan cara di tambang mengunakan alat berat (Excavator)

\section{B. Contrast Streching}

Suatu ukuran citra kontras tertentu disampaikan dalam tulisan ini untuk peningkatan kualitas. Citra kontras adalah bidang yang direnggangkan yang memiliki batas ambang bawah dan ambang atas. Ini adalah sebuah intensitas citra kontras yang mendasarkan metode peningkatan citra pada jarak antar piksel dalam bentuk fungsi $\mathrm{I}(\mathrm{x}, \mathrm{y})=\mathrm{f}(\mathrm{I}(\mathrm{x}, \mathrm{y}))$, dimana citra asli $\mathrm{I}(\mathrm{x}, \mathrm{y})$, dan citra keluaran adalah $\mathrm{I} 0(\mathrm{x}, \mathrm{y})$ setelah peningkatan kontras, dan $f$ adalah fungsi transformasi [4].

Perenggangan kontras adalah suatu metode membuat citra yang memiliki bagian terang menjadi lebih terang dan bagian gelap menjadi lebih gelap [4]. Kontras suatu citra adalah distribusi pixel terang dan gelap. Citra grayscale dengan kontras rendah maka akan terlihat terlalu gelap, terlalu terang atau terlalu abu-abu. Histogram citra dengan kontras rendah, semua pixel akan terkonsentrasi pada sisi kiri, kanan atau di tengah. Semua pixel akan terkelompok secara rapat pada suatu sisi tertentu dan menggunakan sebagian kecil dari semua kemungkinan nilai pixel[16].

$$
S= \begin{cases}l * r & 0<r<a \\ m *(r-a)+v & a<r<b \\ n *(r-b)+w & b<r<L-1\end{cases}
$$

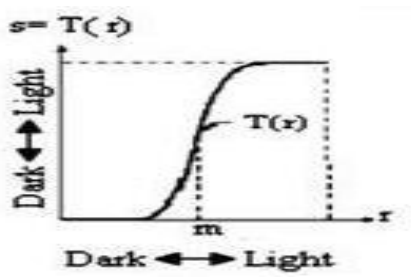

Gbr.2 Contrast Transformation Funtion

Pada Gbr.2. diatas diberikan fungsi transformasi $l, m$ dan $n$ yang adalah lereng yang merupakan tiga daerah yang ditunjukkan pada Gbr.2. Jelas yang $l$ dan $n$ kurang dari satu. $S$ adalah tingkat ke-abu-an dan $\mathrm{r}$ adalah tingkat abu-abuasli. Variabel $a$ dan $b$ adalah batas ambang bawah dan batas ambang atas. Identitas transformasi ditunjukkan oleh garis putus-putus. Kemiringan biru garis diambil 0,5 dan kemiringan garis merah dianggap berjarak 1 atau lebih besar dari 1. sehingga membuat bagian terang menjadi lebih terang dan bagian gelap menjadi lebih gelap.
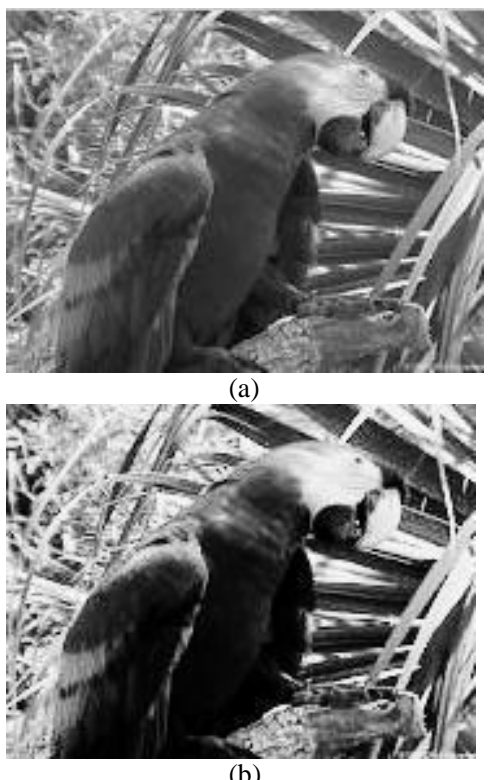

Gbr.3 Contrast Stretching (a) gambar asli (b) gambar yang mengalami stretching

Perenggangan kontras adalah teknik yang sangat berguna untuk memperbaiki kontras citra terutama citra yang memiliki kontras rendah. Teknik ini bekerja dengan baik pada citra yang memiliki distribusi Gaussian atau mendekati distribusi Gaussian.

\section{Klasifikasi}

Klasifikasi adalah proses menemukan model (fungsi) yang menjelaskan dan membedakan kelas-kelas atau konsep, dengan tujuan agar model yang diperoleh dapat digunakan untuk memprediksikan kelas atau objek yang memiliki label kelas tidak diketahui [10].

Klasifikasi pada batu boulder (batu gajah) dapat digunakan berdasarkan ciri - ciri tekstur atau warna yang sama, misalnya batu baik atau kualitas 1 memiliki ciri bertekstur padat dan berwarna keabuan dan hitam, batu burik atau kualitas 2 memiliki ciri bertektur berlubang dan berwarna keabuan dan batu pecel atau kualitas 3 memiliki ciri bertekstur padat dan 
berwarna merah atau keabuan. Untuk pengelompokkan kualitas batu boulder (batu gajah) dapat dilakukan dengan tiga kelas, yaitu kualitas 1, kualitas 2 dan kualitas 3. Hal ini digunakan untuk mengetahui kualitas batu boulder (batu gajah) dan melakukan proses sortir.

\section{ANALISIS DAN PERANCANGAN SISTEM}

\section{A. Analisis Sistem}

Sistem yang akan dibuat dalam penelitian kali ini adalah suatu sistem yang mampu mengklasifikasi kualitas Batu Boulder yang diinputkan oleh admin.

Dalam sistem ini, citra Batu Boulder yang diinputkan oleh admin akan terklasifikasi kualitasnya secara langsung. Pertama admin akan menginputkan citra yang akan digunakan sebagai master yang akan digunakan sebagai pembanding citra. Setelah citra master disimpan, maka pengklasifikasian kualitas Batu Boulder dapat dilakukan. Admin akan menginputkan citra sample ke dalam sistem dan sistem akan membandingkan citra sample dengan citra master. Dan kualitas Batu Boulder akan diketahui.

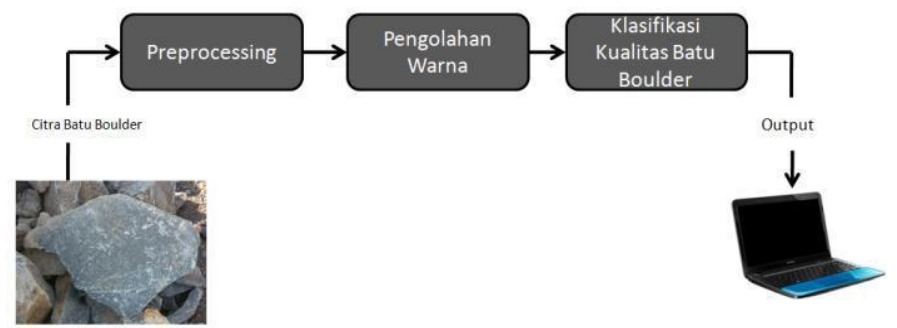

Gbr.4 Model Klasifikasi Kualitas Batu Boulder

Sistem klasifikasi kualitas Batu Boulder terdiri dari tiga blok utama, yaitu: preprocessing, pengolahan warna, dan klasifikasi. Sample akan diolah oleh sistem klasifikasi dan hasilnya berupa klasifikasi kualitas Batu Boulder. Sistem akan dirancang menggunakan tampilan Graphical User Interface sehingga tampil lebih menarik dan mudah dioperasikan.

\section{B. DFD level O (diagram konteks) Sistem Klasifikasi} Batu Boulder

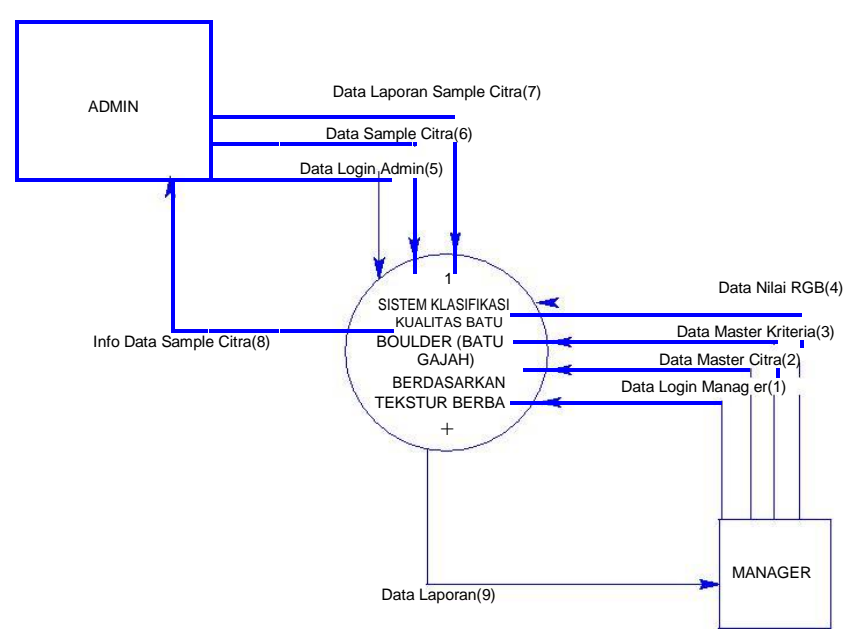

Gbr.5 Contoh DFD Level 0 Sistem Klasifikasi Batu Boulder

\section{DFD Level 1 Sistem Klasifikasi Batu Boulder}

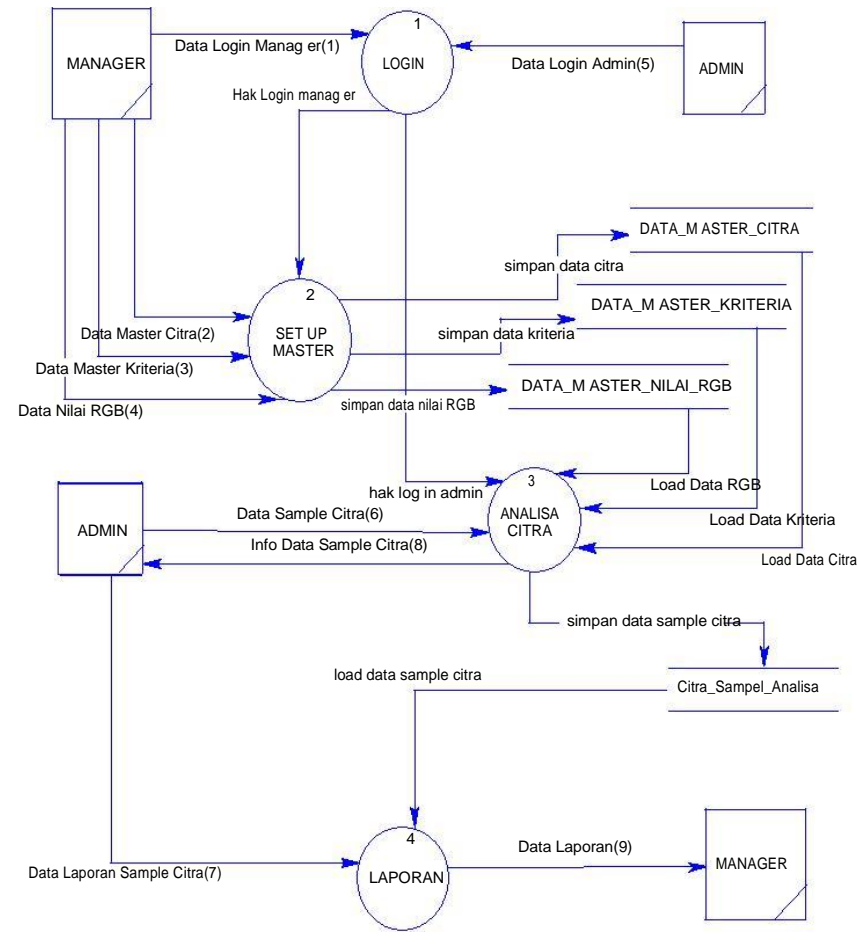

Gbr.6 Contoh DFD Level 1 Sistem Klasifikasi Batu Boulder

\section{Perhitungan Contrast Sretching}

Kualitas citra dengan kontras-rendah dapat diperbaiki dengan operasi peregangan kontras (contrast stretching). Melalui operasi ini, nilai-nilai keabuan piksel akan menjangkau dari 0 sampai 255 (pada citra 8bit), dengan kata lain seluruh nilai keabuan piksel terpakai secara merata.

Cara kerja dari proses peregangan kontras (contrast stretching) pada citra 8bit adalah sebagai berikut.

1. Mengelompokkan dan menghitung jumlah piksel berdasarkan nilai keabuannya (membuat histogram).

2. Memindai (scan) histogram dari nilai keabuan terkecil ke nilai keabuan terbesar (0 sampai 255) untuk menemukan batas nilai keabuan terendahdan batas nilai keabuan tertinggi dari kelompok piksel (citra).

3. Memetakan (menskalakan) piksel - pikselyang berada di antara batas terendah dan batas tertinggi untuk memenuhi rentang nilai - nilai keabuan yang lengkap (0 sampai 255) dengan persamaan :

$$
\mathrm{Y}=\frac{\mathrm{X}-\mathrm{X} 1}{\mathrm{X} 2-\mathrm{X} 1} \times 255 \ldots
$$

Dalam hal ini $Y$ adalah nilai keabuan yang baru/diperoleh, $\mathrm{X}$ adalah nilai keabuan yang lama, 1 adalah nilai keabuan tertinggi dari kelompok piksel dan 2 adalah nilai keabuan terendah dari kelompok piksel. Dengan menggunakan persamaan (4), maka akan didapat nilai keabuan piksel yang baru dengan rentang keabuan $0-255$.

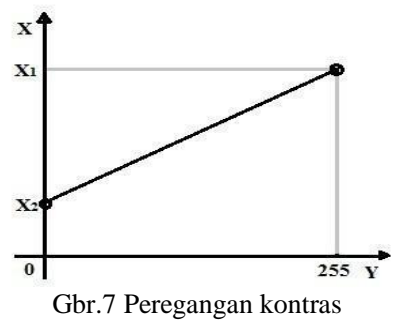


Untuk mendapat hasil peregangan histogram dengan batas terendah dan tertinggi yang dapat diatur, maka digunakan persamaan garis bentuk slope-intercept.

$=\quad+$

Dimana $m$ (slope),

$\mathrm{m}=\frac{\mathrm{y} 2-\mathrm{y} 1}{\mathrm{x} 2-\mathrm{x} 1}$

dan $b$ (intercept),

$=-\mathrm{X}$

dimana $Y$ dan $X$ diambil dari titik pertama, maka

$=1-1$

Oleh karena itu, didapat persamaan:

$$
1+\mathrm{y} 1
$$

Dalam hal ini 1 adalah nilai pengaturan tertinggi piksel yang diinginkan dan 2 adalah nilai pengaturan terendah piksel yang diinginkan.

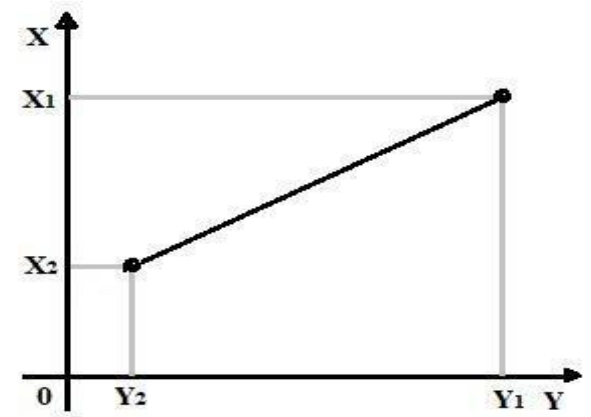

Gbr.8 Peregangan kontras dengan batas dapat diatur

Beberapa Contoh perhitungan Contrast Stretching:

Tabel 1

Contoh perhitungan Contrast Stretching

\begin{tabular}{|c|c|c|c|c|}
\hline NO & $\mathrm{X}_{1}$ & $\mathrm{X}_{2}$ & $\mathrm{Y}_{1}$ & $\mathrm{Y}_{2}$ \\
\hline $\mathbf{1}$ & 180 & 80 & 191 & 155 \\
\hline $\mathbf{2}$ & 200 & 60 & 100 & 22 \\
\hline $\mathbf{3}$ & 180 & 100 & 239 & 36 \\
\hline $\mathbf{4}$ & 160 & 40 & 201 & 72 \\
\hline
\end{tabular}

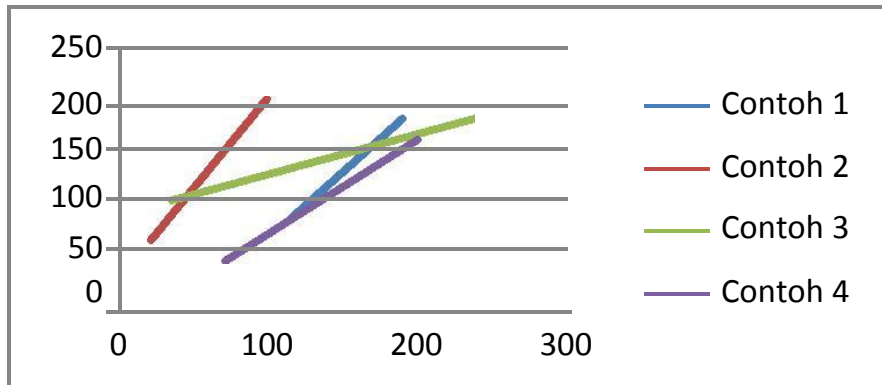

Gbr.9 Grafik perhitungan peregangan kontras

\section{HASIL DAN PENGUJIAN}

Setelah input data master dilakukan, maka dapat dilakukan analisa terhadap sample citra untuk diketahui kualitasnya. Berikut adalah tahapan analisa :

Sample citra dengan Metode Contrast Streching

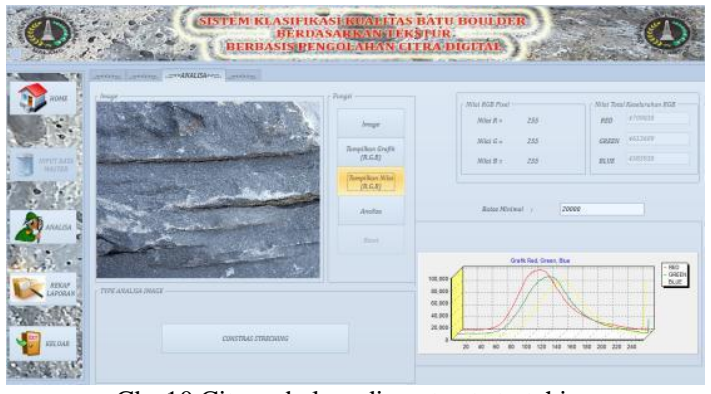

Gbr.10 Citra sebelum di contrast stretching

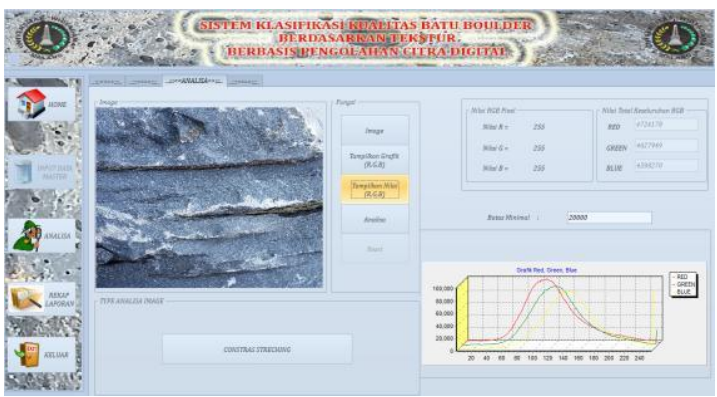

Gbr.11 Citra setelah di contrast stretching

Data sample citra total nilai RGB sebelum contrast stretching pada Gbr.10.

$\mathrm{R}: 4.709 .838$
$\mathrm{G}: 4.613 .609$
$\mathrm{~B}: 4.583 .930$

Total nilai RGB 13.907.377

Data sample citra total nilai RGB sesudah contrast stretching pada Gbr.11.
$\mathrm{R}: 4.724 .178$
$\mathrm{G}: 4.627 .949$
B : 4.598 .270

Total nilai RGB 13.950.397

Setelah kita inputkan citra pada halaman analisa, tahap pertama yang dilakukan adalah contrast stretching, setelah itu kita hitung nilai rgb dan kita tampilkan grafik.

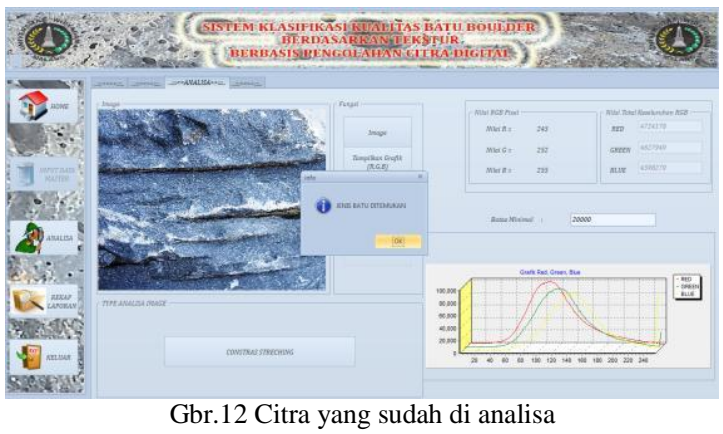


Setelah nilai RGB dan grafik muncul, maka kita tekan tombol analisa. Setelah citra dianalisa akan muncul jendela info, info ynag berisi jenis citra ditemukan atau tidak ditemukan. Setelah di tekan tombol ok maka akan muncul jendela hasil proses analisa batu seperti pada Gbr.13.

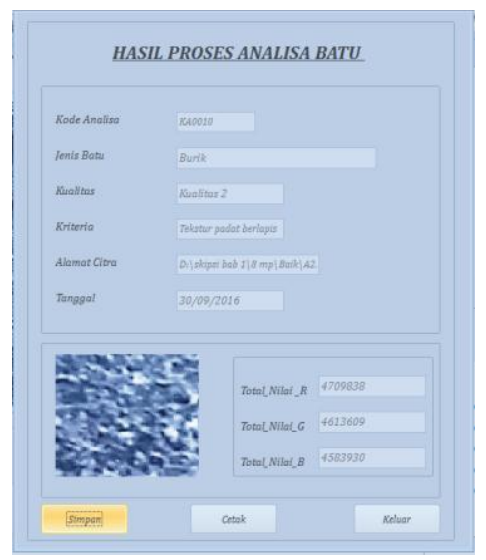

Gbr13 Hasil proses analisa batu

Hasil perhitungan proses analisa batu pada Gbr.13 sebagai berikut:

\begin{tabular}{|c|c|c|c|}
\hline \multicolumn{2}{|l|}{ Sampel } & \multicolumn{2}{|l|}{ Master } \\
\hline Nilai $R$ & 4724178 & \multicolumn{2}{|l|}{ Baik } \\
\hline Nilai_G & 4627949 & Kualitas 1 & 17191848 \\
\hline Nilai $B$ & 4598270 & Kualitas 2 & 13907377 \\
\hline Total & 13950397 & Kualitas 3 & 12979526 \\
\hline \multicolumn{2}{|l|}{ Hasil } & \multicolumn{2}{|l|}{ Burik } \\
\hline Baik & Editzo & Kualitas 1 & 14376778 \\
\hline Kualitas 1 & -3241451 & Kualitas 2 & 13956531 \\
\hline Kualitas 2 & 43020 & Kualitas 3 & 17497757 \\
\hline \multirow{2}{*}{ Kualitas 3} & 970871 & \multicolumn{2}{|l|}{ Pecel } \\
\hline & & Kualitas 1 & 15174988 \\
\hline Burik & Edit22 & Kualitas 2 & 11337746 \\
\hline Kualitas 1 & -426381 & \multirow[t]{4}{*}{ Kualitas 3} & \multirow[t]{4}{*}{14302749} \\
\hline Kualitas 2 & -6134 & & \\
\hline Kualitas 3 & -3547360 & & \\
\hline Pecel & Editz9 & & \\
\hline Kualitas 1 & -1224591 & \multicolumn{2}{|l|}{37625956} \\
\hline Kualitas 2 & 2612651 & \multicolumn{2}{|l|}{ Burik } \\
\hline Kualitas 3 & -352352 & \multicolumn{2}{|l|}{ Kualitas 2} \\
\hline
\end{tabular}

Gbr.14 Hasil Pengujian

Hasil analisa batu pada sample yang didapat mendekati total nilai RGB pada Batu Burik Kualitas 2. Total nilai RGB pada sample 13.950.307 mendekati data master 13.956.531 dari hasil klasifikasi pada Gbr.14.

\section{KESIMPULAN DAN SARAN}

\section{A. Kesimpulan}

Dari pembahasan implementasi sistem klasifikasi batu boulder diatas dapat disimpulkan :

Hasil yang didapat dengan menggunakan metode contrast stretching dan klasifikasi menggunakan total nilai RGB masih tidak merata, karena total nilai RGB dan hasil contrast stretching mempengaruhi nilai total RGB.
Untuk hasil klasifikasi kualitas yang diperoleh dapat mengklasifikasikan data total nilai RGB sample dengan nilai yang mendekati total nilai RGB pada data master.

\section{B. Saran}

Adapun saran dari penyusun skripsi diharapkan dapat lebih meningkatkan hasil yang telah didapatkan adalah sebagai berikut :

Untuk pengembangan bahasa pemrograman mungkin kedepan adanya aplikasi berbasis mobile.

Untuk sistem klasifikasi bisa menggunakan perbandingan metode yang lain agar hasil yang didapat lebih akurat.

\section{REFERENSI}

[1] Alfatta, H. (2007). Analisis dan Perancangan Sistem Informasi Untuk Keunggulan Bersaing Perusahaan dan Organisasi Modern. Yogyakarta: Andi.

[2] Anggraeni, K. (2014, Februari 13). Histogram Citra. Retrieved Maret 20, 2016, from Ilmu Komputer.com: http://www.ilmukomputer.com/

[3] Arham, Z. d. (2004). Evaluasi Mutu Jeruk Nipis (Citrus Aurantifolia Swingle) Dengan Pengolahan Citra Digital Dan Jaringan Syaraf Tiruan. Bogor: ITB.

[4] Balvant Singh, R. S. (2011). Analysis of Contrast Enchancement Techniques For Underwater Image. International Journal of Computer Technology and Electronics Engineering (IJCTEE), Volume 1, Issue 2.

[5] Castleman. (1996). Digital Image Processing. New Jersey: Prentice Hall.

[6] Efford, N. (2000). Digital Image Processing : A Practical Introduction Using JavaTM. Pearson Education.

[7] Haryono, K. A. (2014). Analisis Tekstur Pada Citra Motif Batik Untuk Klasifikasi Menggunakan K-NN. Informatika , 1.

[8] Hestiningsih, I. (2009). Pengolahan Citra Digital. Yogyakarta: Gava Media.

[9] Kadir, A. (2004). Pemrograman Database dengan Delphi 7 Menggunakan Access ADO . Yogyakarta: Andi.

[10] Kamber, J. H. (2006). Data Mining : Concepts and Techniquest. Jim Grey.

[11] Kristanto, A. (2003). Perancangan Sistem Informasi dn Aplikasiya. Yogyakarta: Gava Media.

[12] Munir, R. (2006). Pengolahan Citra Digital dengan Pendekatan Algoritmik. Bandung: Informatika.

[13] Prasetyo, S. A. (2011). Klasifikasi Jenis Pohon Mangga Gadung Dan Curut Berdasarkan Tekstur Daun. Sesindo, 1.

[14] Pribadi, A. F. (2012). Implementasi Metode Contrast Stretching untuk Memperbaiki Contrast Citra. STT Atlas Nusantara, 1.

[15] Pujianto. (2007). Pemograman Borlan Delphi bagi Pemula. Yogyakarta: Graha Ilmu.

[16] Putra, D. (2010). Pengolahan Citra Digital. Yogyakarta: ANDI Offset. 